\title{
Information on Resource Utilisation for Operational Planning in Port Hinterland Transport
}

\author{
Per Wide, Violeta Roso
}

To meet increased freight flows through maritime ports, a high level of resource utilisation in hinterland transport is of crucial importance. However, various perspectives on resource utilisation create issues with use of information for operational decisions in port hinterland. The purpose of this paper is to explore the use of information related to resource utilisation for operational planning in port hinterland freight transport to facilitate its improvement. The study is casebased, and the data is collected through semi-structured interviews, visual observations, and company documents. The findings are analysed with a framework built from literature emphasising different resource utilisation perspectives and the use of information in road freight transport chain decisions. The findings show that the use of information on resource utilisation in operational freight transport decisions in the port hinterland

\section{KEY WORDS}

$\sim$ Port hinterland transport

$\sim$ Resource utilisation

$\sim$ Road freight transport

$\sim$ Logistics service provider

$\sim$ Decision making

$\sim$ Operational planning

Chalmers University of Technology, Department of Technology Management and Economics, Gothenburg, Sweden

e-mail: violeta.roso@chalmers.se

doi: 10.7225/toms.v10.n02.w02

This work is licensed under (cc) BY

Received on: 23.09.2020 / Revised on: 04.06.2021 / Accepted on: 19.07.2021 / Published online: 28.07 .2021 transport system is limited and lacks a complete system overview. Instead of the information on measured parameters, different types of estimates of efficiency parameters (including resource utilisation) are commonly used for operational planning decisions. The information about the measured indicators has to be combined with other information to obtain an efficient level of resource utilisation; otherwise, it could generate incorrect assumptions regarding utilisation. The paper contributes to the topic of operational freight transport planning by describing the use of information on resource utilisation.

\section{INTRODUCTION}

With increasing maritime freight transport, the development in ports and hinterland operations has to be matched. According to Parola et al. (2017), the second most important factor driving port competitiveness after port service costs is port hinterland connectivity. However, despite its importance, hinterland connectivity, i.e. hinterland operations or capacity of inland modes, is usually one of the main barriers in functional intermodal transport chains, resulting in congestion and other sustainability issues (Behdani et al., 2020; Black et al., 2018). High resource utilisation leads to lower transport costs and at the same time reduces environmental impact (Santén, 2016). Furthermore, the energy efficiency of transport increases as resource utilisation increases, creating further incentives for the actors in the system to improve the load factor (Santén et al., 2018). However, actors in the hinterland transport chain are struggling to obtain high resource utilisation (e.g. Behdani et al. (2020); Elbert and Walter (2014). A port's hinterland is not statically determined, but it varies dynamically due to developments in technology, economy, and society; related operational decisions are constantly challenged 
by these dynamic changes (SteadieSeifi et al., 2014), which generate changes in the planned resource utilisation. Hinterland freight transport by road carries with it issues related to resource utilisation in transport route and consolidation decisions, illustrated by a high level of empty running (McKinnon and Ge, 2006) and waiting times at terminals (Jacobsson et al., 2017; Phan and Kim, 2015). Uneven workload at terminals (Murty et al., 2005) contributes to existing problems of low resource utilisation for intermodal terminal operators. Furthermore, Sternberg (2008) demonstrated waste in activities of truck drivers which indicated a potential for better resource utilisation in this area.

Technological advancements such as information communication technologies (ICTs) could provide new opportunities for increasing resource utilisation via efficient freight transport operations (Stefansson, 2006; Elbert and Walter, 2014). These advancements provide improved possibilities in dealing with the dynamic and stochastic nature of operative freight transport (Steadie Seifi et al., 2014) through information exchange and support for decision making during unexpected events (Meyer et al., 2014). So far, information in the hinterland literature has mainly covered planning (e.g. Elbert and Walter, 2014) or synchronisation between actors (e.g., Jacobsson et al., 2018), but research on information as a tool for reporting on resource utilisation (used resources) in order to make it more efficient has been scarce. New technologies could improve information for measuring resource utilisation and for sharing that information with decision makers. Different perspectives on resource utilisation regarding coverage and measurements (Samuelsson and Tilanus, 1997) make it difficult to provide sufficient information to decision makers (Meyer et al., 2014). Therefore, the purpose of this paper is to explore the use of information related to resource utilisation for operational planning in port hinterland freight transport in order to facilitate its improvement. Behdani et al. (2020), in their critical review on port hinterland transport, emphasised the need for research related to capacity optimisation efforts, which are closely related to resource utilisation, in order to lower the environmental footprint of the hinterland transport system.

\section{FRAME OF REFERENCE}

Van Klink and Van den Berg (1998) define a port's hinterland as 'the interior region served by the port' or 'places that can be served by the port more cheaply than from other ports'. For many ports, the weakest link in their transport chain is access to/from their hinterland, where congested roads cause delays (Roso et al., 2019). That, combined with low resource utilisation of transport modes and other resources, contributes to an increase in transport costs, all together influencing the dynamics of the hinterland.

\subsection{Freight Planning Decisions}

Freight transport research has broadly covered decisions taken in the freight transport planning processes (see, e.g. Steadie Seifi et al., 2014, and Guastaroba et al., 2016, for general freight transport planning, and Gumuskaya et al., 2020, for hinterland transport focus). Transport planning decisions can take place on three levels: strategic, tactical, and operational, with each level executing planning at different time horizons, long term, medium term, and short term respectively (Crainic and Laporte, 1997). Additionally, Stank and Goldsby (2000) argued for a decision scope ranging from macro to micro, representing decisions taken considering the whole network and those involving one node or link. Planning on the operational level is highly influenced by conditions set during strategic and tactical planning, e.g. network design (Woxenius, 2007; Guastaroba et al., 2016) or collaboration strategies (Barratt, 2004).

Crainic and Laporte (1997) classify transport planning processes for transport providers (called'carriers') at the operative level into scheduling of services, empty vehicle distribution or repositioning, crew scheduling, and allocation of resources. Service schedules at the tactical level are expressed in detail, including time of departure and arrival from origin to destination and, if applicable, time and length of terminal stops. Less-thanload (LTL) road freight applies time intervals in contrast to shipping lines, which use fixed times for departure. Imbalances in demand, both in amount and time, generate shortages or surpluses of resources such as trailers, containers, and trucks in one node or area (Lumsden, 2006). To deal with these imbalances, planning of empty vehicle distribution and repositioning is needed. Crew scheduling includes, among other things, scheduling for terminal operators and truck drivers to vehicles. For terminal operators, uneven arrival of trucks can generate spread-out workloads that make it difficult to stick to schedules (Murty et al., 2005). Similarly, allocation of resources includes allocating limited resources to tasks to fulfil demand (Crainic and Laporte, 1997). Operational decisions for the terminal operator mainly deal with scheduling incoming and outgoing flows and carriers, assigning carriers to gates (or tracks in rail transport), and temporary storage at nodes (Van Belle et al., 2012; Boysen et al., 2012).

Involvement of many different actors in an intermodal transport chain creates complexity in the sense that it is difficult to track the goods and control the chain. Complexity also increases with the various roles the actors play, e.g. the transport operator can be a road haulier and/or a rail operator, depending on the transport mode in the transport chain. The transport buyer can be either a consignee or a consignor, and the transport service provider role can be taken by the transport coordinator or by the transport operator (Woxenius, 2012). This complicates the understanding of information on resource utilisation as one 
actor can deal with many decisions in a transport chain or only a part of them. Decisions on what to transport as well as the amount and time boundaries are controlled by the transport buyer, and this actor can also dictate how the transport is done, e.g. without consolidation. Time restrictions from the transport buyer could constrain the possibility of consolidation (Stank and Goldsby, 2000). Transport operators dealing with only one link in the transport chain are not responsible for decisions affecting resource utilisation such as what shipments to consolidate and which route to take. However, they might take other decisions affecting resource utilisation, such as what operations to offer in order to keep the vehicle and driver running as much as possible. The logistics service provider deals with demands from the transport buyer and coordinates transport from origin to destination (Wolf and Seuring, 2010). Decisions can be static or dynamic depending on the information available at the time. Static decision problems are solved via one decision (Schönberger, 2011). Dynamic decision problems involve a sequence of decisions needed to achieve the goal; decisions are constrained by earlier and later decisions, and changes in the problems are presented by the environment or by action from a decision maker (Edwards, 1962). Available information for these decisions can be in the form of real-time information (Meyer et al., 2014), such as continuously updated information, or historical data, which could be based on experience (Knemeyer et al., 2009).

\subsection{Resource Utilisation}

Resource utilisation is defined as the ratio of used to available resources, which is seen as part of efficiency according to Caplice and Sheffi (1994). It has also been treated as a part of performance measurement (Shaw, 2009). Performance is similar to efficiency, defined as the ratio between inputs and outputs for a given process. Performance in logistics is usually divided into utilisation, usage of input, productivity, ratio of actual output and input, effectiveness, and quality of output (Caplice and Sheffi, 1994). In this paper, the focus is on utilisation. A resource can be defined by ownership as something a company owns or has access to, including temporary access (Mills et al., 2002) or as a 'factor that has the potential to contribute economic benefit' (Galbreath, 2005: 890). A common classification of resources differentiates between tangible, physical, and financial assets such as buildings and vehicles, and intangible resources such as experience, skills, and intellectual property (Galbreath, 2005). Andersen and Suat Kheam (1998) point out that tangible resources are easily understood as financial or physical resources, but there are differing views on what should be considered as intangible resources.

Resource utilisation is often used in hinterland transport literature to measure efficiency improvements at various port and hinterland setups (Li et al., 2018; Elbert and Walter, 2014). Mainly, the utilisation revolves around the port, e.g. truck waiting or crane utilisation (Li et al., 2018). However, discussions about different perspectives on resource utilisation for transport operations are mainly found in general freight transport literature. Therefore, the following sections include perspectives on resource utilisation for freight transport, focusing on road transport to correspond to the case study described below in this paper.

Resource utilisation is coupled with resources: poor decisions by terminal operators will not only lead to lower resource utilisation at the port terminal, but also to longer waiting times and lower resource utilisation for vehicle and truck drivers. This generates a need to consider resource utilisation from a larger perspective than merely the actor. The system view is of further importance as freight transport often revolves around complex setups of actors and activities (Sternberg et al., 2013), generating trade-offs in objectives for some processes. For example, the owner of a resource such as a trailer for road transport usually aims for a high load factor (capacity utilisation of the vehicle), resulting in the trailer waiting at a terminal until fully loaded (or as much as possible) so that it is still profitable. However, the freight owner might hinder this by demanding shorter lead times (faster transport of goods to the destination). Furthermore, information for resource utilisation can be represented in different ways, adding to the complexity of using the information for planning decisions. Load factor and capacity utilisation are frequently used in freight transport to assess the resource utilisation of a transport mode. This can be done by considering limitations of weight, space/volume, and deck area (McKinnon, 2000). The level of utilisation of one transport mode might change over time, e.g. due to unbalanced flow when a trailer is fully loaded in one direction, but empty on backhaul. Therefore, in the example above, empty running and fuel consumption (McKinnon and Ge, 2004) need to be considered in order to holistically evaluate utilisation of resources. A vehicle travelling completely loaded from on node to another, but coming back empty might be fully utilised from an economical viewpoint if both directions are included in the price, but only half are physically utilised (Lumsden, 2006). In this regard, empty running, according to (McKinnon and Ge, 2004), is an indicator covering capacity and distance.

Samuelsson and Tilanus (1997) provide a comprehensive approach to transport efficiency in which they divide efficiency into factors of time, distance, speed, and capacity, along with the subgroups of each factor. This would not only apply to vehicles, which the authors use as the resource, but also e.g. trailers and terminal operators. Following Samuelsson and Tilanus (1997) approach, this paper takes two perspectives on resource utilisation, one related to the transport route (including time, distance, and speed) and the other related to the unit load (including capacity). These different perspectives on resource utilisation in the literature are summarised in Table 1. 
Table 1.

Summary of different perspectives on resource utilisation in the literature.

Route-related resource utilisation Unit load-related resource utilisation

Amount of time active (vehicle) (McKinnon and Ge, 2004; Physical capacity (Lumsden, 2006)

Samuelsson and Tilanus, 1997)

Efficiency waste by not doing value-added work (Sternberg, Load factor - volume, weight, etc. (McKinnon and Ge, 2004; 2008) Samuelsson and Tilanus, 1997)

Directness (Woxenius, 2012)

Economical capacity (payed load factor, payload) (Lumsden, 2006)

Extra distance (Sanchez Rodrigues, 2014)

Deviation from schedule (McKinnon and Ge, 2004; Samuelsson and Tilanus, 1997)

Fuel consumption, eco driving (McKinnon and Ge, 2004; Díaz-

Ramirez et al., 2017)

McKinnon and Ge (2004) introduced vehicle time utilisation and classified activities into running on road, loading or unloading, waiting for departure, waiting for loading or unloading, maintenance or repair, and driver pause and idle. The perspective of distance includes efficiency problems due to not taking the shortest route, not having a return load, not executing stops in optimal sequence, detours due to round trips, and deviations between planned and actual trip. Woxenius (2012) introduced directness as an indicator for dealing with detours due to disruptions. Similarly, extra distance is introduced due to disruptions in transport operations that change distances (Sanchez Rodrigues, 2014). McKinnon and Ge (2004) emphasise deviations from schedule as this can affect utilisation planning on multiple collection or delivery rounds. The factor of speed includes inefficiency when not driving at maximum speed due to congestion and differences in speed limits. Speed variations can be included as part of eco-driving (Díaz-Ramirez et al., 2017), which is associated with fuel consumption (McKinnon and Ge, 2004). Distance and speed include input and output relations (productivity), but they are important factors in considering how well a resource is being utilised. The capacity and capacity utilisation of a trailer (loading unit) can be measured in various ways from different perspectives such as by volume, weight, floor space occupancy, and height (Santén, 2017). The reasoning behind measuring capacity (load factor) in terms of vehicle level or load unit level has likewise been stressed by McKinnon and Ge (2004) and Santén (2017) respectively.

\section{METHODOLOGY}

To capture the system view, the logistics service provider (LSP) perspective is chosen for this paper due to its coordinating role in freight transport (Ramstedt and Woxenius, 2006). This actor makes dynamic operational decisions which should generate a need for information on resource utilisation. Connections should be provided to other actors proposing a better understanding of resource utilisation from a system view. This research uses a single case study method to explore how information regarding resource utilisation is used in the studied context (Yin, 2014; Eisenhardt, 1989). The case is based on an LSP offering sea transport solutions mainly between Sweden and the UK, in which the regional part of scheduling and consolidation decisions for road hinterland freight transport is the focus of the study. The transport company was chosen as it represents an LSP in a hinterland transport chain in which the LSP's influence on operational decisions is high (Ramstedt and Woxenius, 2006). The chosen company is involved in operational decisions directly linked to the utilisation of both its own resources and those of other actors. The primary data for the study was collected through six semi-structured interviews and through observations during three on-site visits focusing on transport planning and transport operations. Furthermore, the company documents were studied in order to fill in gaps as well as for confirmation of some interview findings. At the company's request, details such as company name and names of the interviewees are not revealed here.

The six semi-structured interviews were around 30-60 minutes long. Four interviews were performed with three freight planners/coordinators, one at each planning group. One of the three planners was interviewed twice as he had knowledge and work experience in two of the planning groups. Additionally, one interview with a planning group manager was done, and one was done with a general manager focusing on follow-up (control) of resource utilisation. The semi-structured interviews with the planners were based on different topics in order to 
cover the purpose of the paper. First, to understand the decisions taken, broader topics were included such as the type of planning executed, how the planning decisions were carried out, and what type of information was used. Thereafter, the focus of the interviews was on the role resource utilisation has in planning and on what kind of information regarding resource utilisation is available, received, and used. This division is made in order to get a better overview of the decisions taken and the information regarding resource utilisation. The interview with the general manger focused on information regarding operational activities at a higher level that were presented to the planners, but not in connection to operational decision making. Only the interview with the general manager was audio recorded as the interviews with the planners took place in an open landscape office, making it difficult to obtain a proper audio recording. All interviews were done face-to-face except for the interview with the planning group manager conducted via telephone. Extensive notes were taken during all interviews. The sample size for interviewees was not fixed beforehand; rather, an evaluation was made of when enough data was collected and saturation was reached (Flick, 2014).

The on-site observations at the freight planning department were conducted on three occasions, giving insight into how the planning was actually performed. Documents for internal reporting were examined to obtain data on information reported to management and quality work.

Research quality was ensured through triangulation of different methods of data collection. Extensive notes from each interview were compiled and shared for confirmation to each responder to avoid incorrect interpretations. All operative freight planning groups at the case company were covered to provide richness of collected data.

\section{FINDINGS AND ANALYSIS}

In this section, the case company and its operational decisions are briefly described, followed by the interview findings, which are analysed and discussed in relation to the frame of reference.

\subsection{Case Description}

The case company delivers import shipments and collects export shipments on trailers via the transport mode road. Trailers arriving at the port are scheduled for distribution by either direct delivery to the customer or other regions, or by consolidation via the regional cross-dock terminal. The collection of shipments is done in the same region in Sweden as planned exports. The plans for these two activities are compiled and modified with the objective of creating a route schedule that combines both deliveries and collections as backhaul to mitigate empty running. The case company acts as a logistics service provider, transport coordinator, and terminal operator, owning 800 trailers and operating cross-dock terminals. Trucks and truck drivers are outsourced to different hauliers.

The operational transport decisions taken at the company are classified into three different planning groups, as illustrated in Table 2. As a consequence of the choice for consolidation of shipments, decisions on what shipments to consolidate are made. Next, route planning is performed in which flows of freight leaving Sweden through the port are combined with import flows to obtain appropriate round trips. Finally, decisions on combining the proposed distribution and collection routes are taken. Additionally, in this decision group, adaptations to the proposed route are made in the case of unforeseen changes in transport activities.

Table 2 .

Illustrating the operational planning groups with main decisions at the case company

Planning groups

Distribution
Main decisions

Direct delivery or consolidation with other shipments

Shipment consolidation for distribution

\section{Collection}

Combining distribution and collection routes into one round trip and assigning resources (contacting haulier)

\section{Shipment consolidation for collection}

Combining distribution and collection route to one drivers' route - contacting haulier to assign route
The decisions are in line with the operational scheduling of services discussed by Crainic and Laporte (1997), being made in real time (Brehmer, 1992). The allocation of resources such as terminal operator and truck driver is performed by other actors, and the control of these decisions is done by the company studied. The control can be in the form of making phone calls to ensure that the haulier has booked the drivers. The planning decisions regarding empty trailer distribution or repositioning 
are included in the different planning groups. The interviews revealed the main focus on costs and customer satisfaction in transport decisions. Furthermore, dangerous goods, loading security, etc. overrule or limit the possibility of achieving high resource utilisation. The operational decisions are built on rules of thumb and experience from conceptual usage of information coming mainly from complaints. For modifications in operations that influenced resource utilisation, the planners were mainly informed via email and phone.

\subsection{Information on Resource Utilisation}

Three main resources influencing planning decisions were identified: trailer $(T)$, truck and truck driver (TD, discussed as one resource), and terminal and terminal operator (TO, discussed as one resource). Considering the resources of a truck and the belonging truck driver as one resource follows the interpretation from the planners who provided the empirical data. The planners plan the truck and the truck driver jointly (as one resource) as the services for these two resources are outsourced to hauliers. The main findings of the case study are summarised in Table 3, and they demonstrate what types of resource information were available and what kinds of resource utilisation the information focused on.
Overall, the received information regarding resource utilisation was scarce for the studied operational decisions. Nevertheless, three types of use for available information were found. First, the information collected and followed up on by management at the case company was input for strategic decisions and not with the aim of providing instant indications of resource utilisation for operational decisions. This could be explained by the fact that the main purpose of this type of information was for documentation, such as ISO, and not to support operational decisions. Examples of this information type are load factor (on outgoing trailers from terminal based on payload from bookings), service level, $\mathrm{CO} 2$ emissions, ecodriving, and truck Euro class. Second, information available for operational planning decisions was found to be based either on forms of real-time information or on information from experience. Regarding real-time information, only information on load factor was identified as available to planners for direct evaluation of resource utilisation. The company's IT system supported the collection of that type of information. These three types of use of available information correspond well with the previous literature findings regarding use of information for real-time decisions (Meyer et al., 2014), experience-based decisions (Knemeyer et al., 2009), and input to strategic decisions (SteadieSeifi et al., 2014).

Table 3

Representation of information available for different types of resources and their utilisation.

Type of resource utilisation Information available for Real-time operational Experience-based planning Input to strategic decisions planning decisions decisions

\begin{tabular}{llll}
\hline Unit load resource utilisation & $\mathrm{TPL}^{*}$ & $\mathrm{TO}$ & $\mathrm{TD}$ \\
\cline { 2 - 4 } & $\mathrm{TO}$ & $\mathrm{TPL}^{*}$ & $\mathrm{TD}$ \\
\hline $\begin{array}{l}\text { Route-related resource } \\
\text { utilisation }\end{array}$ & $\mathrm{TD}$ & $\mathrm{TO}$ & \\
\cline { 2 - 4 } & &
\end{tabular}

\subsubsection{Information on Resource Utilisation Related to Unit Load}

Information regarding unit load is mainly related to the trailer as the resource. The trailer capacity was important for all planning groups, corresponding to the fact that the company owns the trailers and wants high-capacity utilisation of their resources. Information for the expected trailer payload is given directly in the planning process. The observational data in this information is illustrated in Table 4., where each row is a shipment, and the total payload (PL) is summed up. The figure indicates information about resource utilisation directly when a decision of shipment consolidation is made. Importantly, the information does not represent capacity utilisation; for this calculation, the load as capacity for the trailer is needed. Information relevant to planning decisions is provided, but it requires manual combination with other information to obtain capacity utilisation. This leads to a risk of assuming incorrect capacity utilisation if incorrect trailer capacity is assumed. 
Table 4.

Observational data from planning system of the payload for shipments consolidated in one trailer is shown in last column (Fkg), giving direct feedback of filled payload. TBId stands for transport booking ID, and Fkg is the payload. Customers and receivers are hidden due to confidentiality.

\begin{tabular}{llllll} 
TBId & Shipper & & Reciever & FKg \\
\hline 11917822 & SE & AVESTA & GB & CRADLEY & 18400 \\
\hline 11637822 & SE & LUDVIKA & GB & HEREFORD & 800 \\
\hline 11651822 & SE & LUDVIKA & GB & HEREFORD & 600 \\
\hline 11960823 & SE & KIL & GB & SITTINGBOURNE & 130 \\
\hline 11803822 & SE & KRISTINEHAMN & GB & BIRMINGHAM & 800 \\
\hline 12758822 & SE & GOTEBORG & GB & COLCHESTER & 135 \\
\hline 11351822 & SE & TORSAS & GB & NEWTON AYCLIFFE & 262 \\
\hline 12780822 & SE & BORAS & GB & BRADFORD & 3200 \\
\hline
\end{tabular}

The payload in Table 4. is calculated by adding planned shipments based on either weight, volume or load meter (based on length) of the shipment (taken from transport booking), depending on which one is the most limiting and generates the highest price. Importantly, this is the chargeable weight payload based on the transport bookings and not the actual load. The payload and the booking parameters may differ from the actual load at pick-up. Interestingly, there seems to be no clear objective, desired level for the payload. This can partly be explained as the received information has to be combined with trailer capacity, and even then, it only represents one part of capacity (not actual capacity used), making the whole resource utilisation (or efficiency) problematic. Using this information as a base for resource utilisation in consolidation decisions considers only one aspect of capacity utilisation (payload).

An actual filled load is more difficult to obtain than payload as it demands information for resource utilisation after pickup has occurred. For example, if a planned shipment includes four pallets, but at pick-up three or even five are loaded, the information about the new load factor needs to be obtained. To measure the actual load may require extra work or technical implementation. Monthly reports on average payload are presented to planners, but they are mainly used to ensure that planners are aware of the importance of payload factor in order to make decisions on strategic and tactical levels as well as to convince others that the planning is going well. This kind of information makes connections to specific operational decisions difficult. The information reported monthly or quarterly usually focuses on important aspects at a higher strategic level, e.g. achieving a high economic payload on the sea portion of the transport chain and not focusing on each route performed. Additionally, the capacity of the terminal may be considered if the planner, through experience, knows that during some hours or days the terminal is usually busy; they can plan without driving via terminal to avoid high demand. This reasoning in planning can affect the utilisation of the trailers in a negative way as they perform transport directly without using consolidation to increase capacity utilisation. As the terminal is operated by the case company, more emphasis on a system view, including the terminal needs, can be expected. Specific information about workload at the terminal regarding capacity and time was not identified, but using complaints from the terminal as information brought experience into the equation regarding terminal workload. In this way, experience was used rather than the information on actual workload for a specific day.

\subsubsection{Information on Resource Utilisation Related to the Route}

The resource of truck and truck driver was considered when making route decisions. Some planners mentioned that they want to keep a good relationship with their hauliers and so generate routes that allow them to get good utilisation of the truck (and driver) for one working day. Complaints were received via phone from hauliers about bad or inappropriate features on routes. This worked as information, not in the form of any measured indicator, but conceptually to understand truck drivers' problems with routes. These problems were e.g. insufficient driver resting schedules and the need to return to origin by the end of the day. The planning group with the main responsibility for haulier and truck driver contact emphasised this point to a higher degree than the other groups as they probably receive most of the feedback from hauliers. Regarding information on the distance, the trailer resource was the focus. Knowledge about the distance 
between stops combined with estimated times for loading and unloading (at customer, pick-up at supplier or terminal) directly provides estimated times for planning. No measured indicator as information for this was evident. This also illustrates previous reasoning regarding the lack of a desired level of utilisation. Varied experiences lead to different buffers being built into the planning so as to cope with unexpected events. Distance was also mentioned in regard to empty running in connection to the trailer resource, but without any information about distance or empty running. Empty running was estimated via distance and payload from the planners to obtain an overview. Furthermore, as mentioned above, time utilisation by terminal and terminal operators was included in the planning decisions with the intention of spreading out the terminal workload. No specific measured indicator was found for this, only complaints from the terminal that provided experience.

The impact of decisions on the environment was not mentioned by the interviewees. However, other main objectives provide good side effects for the environment, such as lower fuel consumption. Environmental indicators of emissions and fuel usage (from haulier) were collected on tactical levels, but not used directly in operational decisions.

\subsubsection{System View on Usage of Indicators for Resource Utilisation}

The information for the studied operational decisions is limited in covering all perspectives of resource utilisation, as can be seen in Table 3. The system view of utilisation is limited in representing the complete picture of resource utilisation in hinterland transport. The case company focuses on unit load capacity in terms of payload instead of on broader utilisation coverage of actual capacity (based on actual weight) used. The studied case, therefore, lacks a broad coverage of capacity, pointed out to be important for sufficient indication of capacity (McKinnon and Ge, 2004; Lumsden, 2006).

By using limited information about resource utilisation, the case company may obtain an incorrect impression of their resource utilisation, such as how well they are utilising their trailers. Additionally, the environmental concerns related to resource utilisation (e.g., (McKinnon and Ge, 2004; Díaz-Ramirez et al., 2017) had no linked information at the operative planning level. Rather, to satisfy customer needs, customer service had priority in planning, in contrast to the perception in the literature of plans being made to achieve environmentally positive (McKinnon and Ge, 2004) or shortest route (Woxenius, 2012) targets.

The planners take resources from other actors into account, which should suggest resource utilisation models that cover perspectives of many actors' resources as being more practically suitable. However, information about utilisation of these resources is mainly based on experience within the case company and lacks the integration of other actors in the planning process. The complex setups of transport planning examined by Sternberg et al. (2013) make the consideration of other actors difficult. Information exchange between actors could provide possibilities to compile more detailed information, adding a new dimension to the current data. To avoid suboptimal solutions, information with broader system views of actors and utilisation are needed. Furthermore, ICT could support information about resource utilisation. This is important for planners to connect resource utilisation to a specific decision. Most decisions are based on experience of 'what works', and little information about resource utilisation is given in connection to the decisions. As indicated by Meyer et al. (2014), this points towards the importance of closing information gaps in operational planning in order to improve operational transport decisions.

In line with Meyer et al. (2014), the issue of providing updated information during unexpected events in operations is salient. Lack of information about resource utilisation during operative planning additionally limits the ability to effectively deal with dynamic operative decisions as indicated by Steadie Seifi et al. (2014). If re-plan adjustments are made to the original plan due to unexpected events during transport operations, resource utilisation is influenced and needs to be updated. The lack of updated, direct information on resource utilisation for planners impedes the ability of planners to understand the replan decision's impact on resource utilisation. The focus may not be on providing only a feasible plan after the unexpected event (Meyer et al., 2014; Li et al., 2018), but a feasible plan without too much negative impact on resource utilisation. Since the planners lack this information, it is difficult to know how much the new plan will impact resource utilisation, either positively or negatively.

\section{CONCLUSION}

Operational decisions by a logistics service provider were examined from the perspective of using information on resource utilisation. The purpose of this paper was to explore the use of information related to resource utilisation for operational planning in hinterland freight transport in order to facilitate its improvement. A case study was designed around a hinterland LSP to capture information regarding resource utilisation for hinterland transport decisions. Findings from the case study show that consideration of information on resource utilisation in transport decisions is limited at the case company. Estimations based on experience of efficiency parameters, including resource utilisation, are used instead of measured parameters as information for operational decisions. 
The study suggests that information with a broader system view is not used in operational decisions. The information used does not give a full picture of resource utilisation, only payload for capacity, which limits the possibility of covering resource utilisation appropriately in decisions. Furthermore, actual resource utilisation is not known exactly, but is estimated from available data that represent a combination of different types of information, potentially generating the risk of incorrect assumptions regarding resource utilisation. These insights about information around resource utilisation provide theoretical contribution to hinterland transport literature by broadening the view of information to resource utilisation instead of considering information for planning purpose or synchronisation between actors. While practical contribution is in increased understanding on information around resource utilisation, transport and logistics managers can use the different viewpoints of resource utilisation to understand how their current use of information in the operational planning provides support to their planners.

Advancements in ICT could provide possibilities for better measuring utilisation with more precise information. The results point towards lack of measurements, which limits the information on resource utilisation. This implies that further research is needed on how to use ICT to measure and share utilisation and information. The results further imply that the LSP should consider how ICT can be used to enable direct information sharing for resource utilisation when something unexpected occurs. Finally, information for resource utilisation that includes a broader system view could contribute to information sharing in freight transport literature, where information is not only playing a role in changing and directly improving activities for some actor(s), but contributes to the resource utilisation when unexpected events occur.

The limitation on the generalisability of a single case study can be addressed by future research investigating a similar approach with other actors or transport setups. Furthermore, the findings in this paper rely on qualitative data, which can be used for setup of future quantitative studies. Future research could start with the lack of information around re-planning identified in this study, e.g. information about when to re-plan, and how the re-plan will impact the planned resource utilisation.

\section{ACKNOWLEDGMENT}

This research was funded in part by the EU Interreg Öresund-Kattegat-Skagerrak Value2Sea project.

\section{REFERENCES}

Andersen, O. \& Suat Kheam, L., 1998. Resource-based theory and international growth strategies: an exploratory study. International Business Review, 7(2), pp.163184. Available at:

http://dx.doi.org/10.1016/s0969-5931(98)00004-3.
Barratt, M., 2004. Understanding the meaning of collaboration in the supply chain. Supply Chain Management: An International Journal, 9(1), pp.30-42. Available at: http://dx.doi.org/10.1108/13598540410517566.

Behdani, B. et al., 2020. Port-hinterland transport and logistics: emerging trends and frontier research. Maritime Economics \& Logistics, 22(1), pp.1-25. Available at: http://dx.doi.org/10.1057/s41278-019-00137-3.

Black, J. et al., 2018. Issues in Dry Port Location and Implementation in Metropolitan Areas: The Case of Sydney, Australia. Transactions on Maritime Science, 7(1), pp.4150. Available at:

http://dx.doi.org/10.7225/toms.v07.n01.004.

Boysen, N. et al., 2012. Shunting yard operations: Theoretical aspects and applications. European Journal of Operational Research, 220(1), pp.1-14. Available at: http://dx.doi.org/10.1016/j.ejor.2012.01.043.

Brehmer, B., 1992. Dynamic decision making: Human control of complex systems. Acta Psychologica, 81(3), pp.211-241. Available at: http://dx.doi.org/10.1016/0001-6918(92)90019-a.

Caplice, C. \& Sheffi, Y., 1994. A Review and Evaluation of Logistics Metrics. The International Journal of Logistics Management, 5(2), pp.11-28. Available at: http://dx.doi.org/10.1108/09574099410805171.

Caplice, C. \& Sheffi, Y., 1994. A Review and Evaluation of Logistics Metrics. The International Journal of Logistics Management, 5(2), pp.11-28. Available at: http://dx.doi.org/10.1108/09574099410805171.

Díaz-Ramirez, J. et al., 2017. Eco-driving key factors that influence fuel consumption in heavy-truck fleets: A Colombian case. Transportation Research Part D: Transport and Environment, 56, pp.258-270. Available at: http://dx.doi.org/10.1016/j.trd.2017.08.012.

Edwards, W., 1962. Dynamic Decision Theory and Probabilistic Information Processings. Human Factors: The Journal of the Human Factors and Ergonomics Society, 4(2), pp.59-74. Available at:

http://dx.doi.org/10.1177/001872086200400201

Eisenhardt, K.M., 1989. Building Theories from Case Study Research. The Academy of Management Review, 14(4), p.532. Available at: http://dx.doi.org/10.2307/258557.

Elbert, R. \& Walter, F., 2014. Information flow along the maritime transport chain - a simulation based approach to determine impacts of estimated time of arrival messages on the capacity utilization. Proceedings of the Winter Simulation Conference 2014. Available at:

http://dx.doi.org/10.1109/wsc.2014.7020028.

Flick, U., 2014. An introduction to qualitative research, Sage publiations.

Galbreath, J., 2005. Which resources matter the most to firm success? An exploratory study of resource-based theory. Technovation, 25(9), pp.979-987. Available at: http://dx.doi.org/10.1016/j.technovation.2004.02.008.

Guastaroba, G., Speranza, M.G. \& Vigo, D., 2016. Intermediate Facilities in Freight Transportation Planning: A Survey. Transportation Science, 50(3), pp.763-789. Available at:

http://dx.doi.org/10.1287/trsc.2015.0631

Gumuskaya, V. et al., 2020. A framework for modelling and analysing coordination challenges in hinterland transport systems. Maritime Economics \& Logistics, 22(1), pp.124-145. Available at:

http://dx.doi.org/10.1057/s41278-019-00139-1.

Jacobsson, S., Arnäs, P.O. \& Stefansson, G., 2017. Access management in intermodal freight transportation: An explorative study of information attributes, actors, 
resources and activities. Research in Transportation Business \& Management, 23, pp.106-124. Available at:

http://dx.doi.org/10.1016/j.rtbm.2017.02.012.

Jacobsson, S., Arnäs, P.O. \& Stefansson, G., 2018. Differentiation of access management services at seaport terminals: Facilitating potential improvements for road hauliers. Journal of Transport Geography, 70, pp.256-264. Available at: http://dx.doi.org/10.1016/j.jtrangeo.2018.06.009.

Knemeyer, A.M., Zinn, W. \& Eroglu, C., 2008. Proactive planning for catastrophic events in supply chains. Journal of Operations Management, 27(2), pp.141-153. Available at:

http://dx.doi.org/10.1016/j.jom.2008.06.002.

Li, N. et al., 2018. Disruption management for truck appointment system at a container terminal: A green initiative. Transportation Research Part D: Transport and Environment, 61, pp.261-273. Available at: http://dx.doi.org/10.1016/j.trd.2015.12.014.

Lumsden, K., 2006. Logistikens grunder: Teknisk logistik, Studentlitteratur, ISBN: 9789144124827

Mckinnon, A., 2000. Sustainable distribution: Opportunities to improve vehicle loading. Industry and Environment, Vol. 23 No. 4, pp. 26-27.

McKinnon, A.C. \& Ge, Y., 2004. Use of a synchronised vehicle audit to determine opportunities for improving transport efficiency in a supply chain. International Journal of Logistics Research and Applications, 7(3), pp.219-238. Available at: http://dx.doi.org/10.1080/13675560412331298473.

McKinnon, A.C. \& Ge, Y., 2006. The potential for reducing empty running by trucks: a retrospective analysis. International Journal of Physical Distribution \& Logistics Management, 36(5), pp.391-410. Available at:

http://dx.doi.org/10.1108/09600030610676268.

G. Meyer, G. et al., 2014. Intelligent products for enhancing the utilization of tracking technology in transportation. International Journal of Operations \& Production Management, 34(4), pp.422-446. Available at: http://dx.doi.org/10.1108/ijopm-11-2012-0530.

Mills, J. et al., 2002. Strategy and Performance. Available at: http://dx.doi.org/10.1017/cbo9780511754692.

Murty, K.G. et al., 2005. A decision support system for operations in a container terminal. Decision Support Systems, 39(3), pp.309-332. Available at: http://dx.doi.org/10.1016/j.dss.2003.11.002.

Parola, F. et al., 2016. The drivers of port competitiveness: a critical review. Transport Reviews, 37(1), pp.116-138. Available at: http://dx.doi.org/10.1080/01441647.2016.1231232.

Phan, M.-H. \& Kim, K.H., 2015. Negotiating truck arrival times among trucking companies and a container terminal. Transportation Research Part E: Logistics and Transportation Review, 75, pp.132-144. Available at: http://dx.doi.org/10.1016/j.tre.2015.01.004.

Ramstedt, L., Woxenius, J., 2006. Modelling approaches to operational decisionmaking in freight transport chains. Proceedings from the NOFOMA 2006 conference, 8-9 June, Oslo.

Roso, V., Russell, D. \& Rhoades, D., 2019. Diffusion of Innovation Assessment of Adoption of the Dry Port Concept. Transactions on Maritime Science, 8(1), pp.26-36. Available at:

http://dx.doi.org/10.7225/toms.v08.n01.003.
Samuelsson, A. \& Tilanus, B., 1997. A framework efficiency model for goods transportation, with an application to regional less-than-truckload distribution. Transport Logistics, 1(2), pp.139-151. Available at: http://dx.doi.org/10.1163/156857097300151660.

Sanchez Rodrigues, V. et al., 2014. Developing "Extra Distance" as a measure for the evaluation of road freight transport performance. International Journal of Productivity and Performance Management, 63(7), pp.822-840. Available at: http://dx.doi.org/10.1108/ijppm-05-2013-0091.

Santén, V., 2016. Towards environmentally sustainable freight transport - shippers' logistics actions to improve load factor performance, Doctoral Thesis, Chalmers University of Technology.

Santén, V., 2017. Towards more efficient logistics: increasing load factor in a shipper's road transport. The International Journal of Logistics Management, 28(2), pp.228-250. Available at: http://dx.doi.org/10.1108/ijlm-04-2015-0071.

Santén, V., et al., 2018. Energieffektivisering genom ökad fyllnadsgrad sjötransporter.

Schönberger, J., 2011. Model-based control of logistics processes in volatile environments, Springer-Verlag New York Inc., ISBN: 9781441996817.

Shaw, E.H., 2009. A general theory of systems performance criteria. International Journal of General Systems, 38(8), pp.851-869. Available at: http://dx.doi.org/10.1080/03081070903270543.

Stank, T.P. \& Goldsby, T.J., 2000. A framework for transportation decision making in an integrated supply chain. Supply Chain Management: An International Journal, 5(2), pp.71-78. Available at: http://dx.doi.org/10.1108/13598540010319984.

SteadieSeifi, M. et al., 2014. Multimodal freight transportation planning: A literature review. European Journal of Operational Research, 233(1), pp.1-15. Available at: http://dx.doi.org/10.1016/j.ejor.2013.06.055.

Stefansson, G., 2006. Collaborative logistics management and the role of third-party service providers B. Gammelgaard, ed. International Journal of Physical Distribution \& Logistics Management, 36(2), pp.76-92. Available at: http://dx.doi.org/10.1108/09600030610656413.

Sternberg, H., 2008. Transportation visibility and information sharing: A case study of actors' requirements. World Review of Intermodal Transportation Research, 2(1), pp. 54-71. Available at: https://doi.org/10.1504/writr.2008.021485.

Sternberg, H., Germann, T. \& Klaas-Wissing, T., 2013. Who controls the fleet? Initial insights into road freight transport planning and control from an industrial network perspective. International Journal of Logistics Research and Applications, 16(6), pp.493-505. Available at:

http://dx.doi.org/10.1080/13675567.2013.856391.

Sternberg, H., Prockl, G. \& Holmström, J., 2014. The efficiency potential of ICT in haulier operations. Computers in Industry, 65(8), pp.1161-1168. Available at: http://dx.doi.org/10.1016/j.compind.2014.07.002.

Van Belle, J., Valckenaers, P. \& Cattrysse, D., 2012. Cross-docking: State of the art. Omega, 40(6), pp.827-846. Available at: http://dx.doi.org/10.1016/j.omega.2012.01.005.

Van Belle, J., Valckenaers, P. \& Cattrysse, D., 2012. Cross-docking: State of the art. Omega, 40(6), pp.827-846. Available at: http://dx.doi.org/10.1016/j.omega.2012.01.005. 
Wolf, C. \& Seuring, S., 2010. Environmental impacts as buying criteria for third party logistical services Á. Halldórsson, ed. International Journal of Physical Distribution \& Logistics Management, 40(1/2), pp.84-102. Available at:

http://dx.doi.org/10.1108/09600031011020377.

Woxenius, J., 2007. Generic Framework for Transport Network Designs: Applications and Treatment in Intermodal Freight Transport Literature. Transport Reviews, 27(6), pp.733-749. Available at:

http://dx.doi.org/10.1080/01441640701358796.

Woxenius, J., 2012. Directness as a key performance indicator for freight transport chains. Research in Transportation Economics, 36(1), pp.63-72. Available at: http://dx.doi.org/10.1016/j.retrec.2012.03.007.

Yin, R.K., 2014. Case Study Research Design and Methods (5th ed.), Sage publications. 